\title{
LA OPERACIÓN ACORDEÓN EN EL ÁMBITO \\ SOCIETARIO
}

\author{
THE ACCORDION OPERATION IN THE CORPORATE LAWYER FIELD \\ Daniel Echaiz Moreno \\ Universidad de Lima \\ Lima-Perú
}

Recibido: 28 de junio de 2013. Aceptado: 04 de julio de 2013.

\section{Peliminar}

Con fecha 5 de abril del 2011 se publicó en el Diario Oficial El Peruano la Sentencia del Tribunal Constitucional, de fecha 4 de abril del mismo año, recaída en el Expediente $\mathrm{N}^{\circ}$ 00228-2009-PA/TC-La Libertad, mediante la cual se declara fundado el recurso de agravio constitucional interpuesto por Flor de María lbañez Salvador contra la Resolución de la Sala Constitucional y Social Permanente de la Corte Suprema de Justicia de la República, de fecha 17 de septiembre del 2008, que declaró improcedente la demanda de amparo interpuesta contra la Empresa Agraria Chiquitoy S.A., el Complejo Industrial Cartavio S.A.A., el Fondo de Inversiones Diversificadas S.A. (FODINSA), el

Instituto Nacional de Defensa de la Competencia y de la Protección de la Propiedad Intelectual (INDECOPI) y la Procuraduría Pública de la Oficina de la Presidencia del Consejo de Ministros.

En dicho caso se obtuvieron tres votos a favor de la posición que declaró fundado el mencionado recurso de agravio constitucional y tres votos a favor de la posición que lo declaró improcedente. No obstante, la primera posición se constituye en sentencia porque la Resolución Administrativa $\quad \mathrm{N}^{\circ}$ D $028-2011-\mathrm{PITC}$, publicada en el Diario Oficial El Peruano el 22 de marzo del 2011, incorporó el artículo 10-A al Reglamento Normativo del Tribunal Constitucional, mediante el cual se establece que el Presidente del Tribunal Constitucional tiene el voto decisorio en los casos que se produzca empate en la votación de causas vistas por el Pleno.

La referida sentencia constitucional es histórica en el Perú puesto que en ella se aborda por primera vez en nuestro país a nivel de la jurisprudencia constitucional un cautivante tema del Derecho Societario contemporáneo, conocido usualmente en el mercado como "la operación acordeón", que acarrea importantes consecuencias jurídicas, por ejemplo, en cuanto al derecho de suscripción preferente. Al cabo de 51 páginas y 74 considerandos, el Tribunal Constitucional declara fundada la demanda por haberse vulnerado los derechos de propiedad, libre iniciativa privada, asociación, debido proceso corporativo privado e interdicción a la arbitrariedad, ordenando a las empresas emplazadas que cumplan con restituir a la demandante la titularidad de todas las acciones que poseía en la Empresa Agraria Chiquitoy S.A. Ante su derrota, esta compañía solicitó la aclaración de la sentencia, pedido que fuera declarado improcedente mediante Resolución del Tribunal Constitucional de fecha 18 de abril del 2011 y publicado en el Diario Oficial El Peruano una semana después, es decir, el 25 de abril del mencionado año.

Es de mencionar que nos sentimos plenamente identificados con este caso (que 
se extendió durante más de cuatro años) porque el suscrito ha sido el abogado defensor de la demandante, quien ha resultado finalmente victoriosa; nuestro trabajo comprendió desde el informe oral ante el INDECOPI que realizamos en la ciudad de Trujillo en el 2006 hasta el informe oral que efectuamos ante el Pleno del Tribunal Constitucional en sesión descentralizada en la ciudad de Pucallpa en el 2009, entre otras actuaciones procesales. Ello explica que tengamos acceso a documentos que obran en el expediente y que ilustran de mejor manera la comprensión de la sentencia sub-examine. Al haber sido gentilmente invitados a participar en esta Revista con el presente análisis y comentario jurisprudencial deseamos exponer algunas anotaciones tras bambalinas que justifican plenamente el sentido del fallo constitucional y que ofrecemos a razón de nuestra particular posición, en la que el suscrito ha sido el abogado de la demandante, de manera tal que no nos avocaremos con prolijidad a la operación acordeón sino más bien a las cuestiones jurídicas vinculadas al presente caso y que se vieron afectadas por dicha operación.

\section{El caso}

Con fecha 16 de noviembre del 2006 se convocó a junta de acreedores de la Empresa Agraria Chiquitoy S.A. mediante aviso publicado en el Diario Oficial El Peruano, formando parte de la agenda los siguientes puntos 3 , 4 y 5 :

1. Modificación del Plan de Reestructuración.

2. Reducción del capital por restablecimiento del equilibrio entre el capital social y el patrimonio neto disminuidos por consecuencia de pérdidas.

3. Aumento de capital por capitalización de créditos.

En dicho aviso también se convocó a los accionistas de la mencionada Empresa Agraria Chiquitoy S.A., a fin de que los mismos "ejerzan su derecho de suscripción preferente, de acuerdo a lo establecido en el artículo 68 de la Ley [General del Sistema Concursal]".

Con fecha 6 de diciembre del 2006 se llevó a cabo la junta de acreedores, en la cual estuvo representado el $81.8220 \%$ de acreedores, contando con la participación de Flor de María Ibañez Salvador por derecho propio y en representación de Martín Alfredo Aguayo Risco, ambos accionistas de la concursada Empresa Agraria Chiquitoy S.A.

En la referida junta de acreedores, según consta en el acápite 3 del Informe de la Junta de Acreedores, emitido por el representante de la Comisión de Procedimientos Concursales del INDECOPI de La Libertad, Juan Miguel Tejada Lombardi, con fecha 6 de diciembre del 2006, se leyó la propuesta de modificación del Plan de Restructuración, la que importaba "la posibilidad que se capitalicen 1 millón de soles FODINSA y 1 millón de soles Complejo Agroindustrial Cartavio S.A.A.". En el mismo acápite 3 del referido Informe de Junta de Acreedores, en el punto "Ejercicio del derecho de suscripción preferente por los accionistas de [Empresa Agraria] Chiquitoy [S.A.]" se señala:

"Se admitirá de conformidad con el artículo 68.1 de la LGSC [Ley General del Sistema Concursal] que el aumento de capital antes descrito puede ser cubierto preferentemente por los accionistas de [Empresa Agraria] Chiquitoy [S.A.] a prorrata de la participación que tenían antes de la reducción del capital social a cero.

Si los accionistas no hicieran uso de este derecho, la integridad del aumento de capital será suscrito por los acreedores de Clase $\mathrm{C}$, conforme a lo establecido en el numeral 3.1 de la presente [Adenda].

En caso que los accionistas de [Empresa Agraria] Chiquitoy [S.A.] decidan suscribir parcial o totalmente el aumento de capital aquí previsto en la oportunidad para lo cual han sido convocados, es decir, tal como lo dispone el artículo 68.1 de la LGSC [Ley General del Sistema Concursal] en la misma fecha de la 
aprobación de la presente Adenda 1 . Esto lo deberá realizar inmediatamente, el pago integro del aporte en efectivo. Si los accionistas no cumplen con pagar inmediatamente las nuevas acciones que hubieran suscrito, el monto de dicha suscripción no pagada será suscrita y pagada por los acreedores de la Clase C. En el caso de que los actuales accionistas de [Empresa Agraria] Chiquitoy [S.A.] suscriban y paguen parcialmente el aumento de capital, el monto a capitalizar por parte de los acreedores se reducirá a prorrata y el monto no capitalizado recibirá el tratamiento que corresponda según el Plan [de Reestructuración].

En los casos en que los accionistas de [Empresa Agraria] Chiquitoy [S.A.] ejerzan su derecho de suscripción preferente, los recursos que éstos entreguen como aportes del capital serán utilizados para la cancelación de los créditos concursales reconocidos a prorrata, debiendo respetarse las reglas establecidas en el artículo 66.4 de la LGSC [Ley General del Sistema Concursal] para el pago de las acreencias laborales."

Según continúa el Informe de Junta de Acreedores, cuando recién se terminó de leer la propuesta de modificación del Plan de Reestructuración, el presidente de la junta de acreedores consultó a los asistentes "si alguien desea realizar un comentario o aporte adicional", oportunidad en la que la socia Flor de María Ibañez Salvador expresó: "Señor presidente, yo soy accionista, estoy interesada en hacer la suscripción de acciones" (el resaltado es nuestro). Ante esto, el aludido presidente de la junta de acreedores le respondió: "Que hubiera manifestado antes al momento de la votación". La socia Flor de María Ibañez Salvador replicó que ya le había indicado al representante del INDECOPI, lo cual fue confirmado por el presidente de la citada junta; no obstante, éste señaló que "ya se había realizado la votación, por lo que propuso un cuarto intermedio".
Reanudada la sesión y ante la insistencia de la socia Flor de María Ibañez Salvador, en el Informe de Junta de Acreedores se contempla que el presidente de la junta de acreedores expresó: "Que ha realizado consultas de índole legal y le han informado que ese asunto ya ha sido cerrado, estamos en el siguiente punto de agenda, de acuerdo a nuestra propuesta inicial se concedía este derecho a las personas que fueron accionistas, yo creo que en ese momento se ha debido hablar del tema, ya la votación ha sucedido. Proseguimos con la junta...".

Finalmente, consta en el mencionado Informe de Junta de Acreedores que "el presidente [de la junta de acreedores]" le rogó [a la socia Flor de María Ibañez Salvador] que no interrumpa a las personas que están exponiendo y que ese ya era un tema pasado". Cabe precisar que, según se aprecia en el propio Informe de Junta de Acreedores, la mencionada socia Flor de María Ibañez Salvador manifestó su disconformidad con que prosiga la junta de acreedores sin haberse satisfecho su pedido. Ella pretendía ejercer su derecho de suscripción preferente que por ley le correspondía para, por un lado, mantener la proporción de su participación en el capital social de la concursada Empresa Agraria Chiquitoy S.A., de modo que no se pierda su inversión como posteriormente sucedió y, por otro, financiar a la propia concursada Empresa Agraria Chiquitoy S.A. para que cumpla con el pago de sus deudas, consiguiendo así su reflotamiento en el mercado que es la finalidad del procedimiento concursal.

Ante esas circunstancias, la socia Flor de María Ibañez Salvador impugnó los acuerdos adoptados en la mencionada junta de acreedores de fecha 6 de diciembre del 2006. La Comisión de Procedimientos Concursales del INDECOPI de La Libertad falló declarando infundada la impugnación, resolución que fue apelada ante el Tribunal del INDECOPI. Posteriormente, con fecha 7 de diciembre del 2007 se interpone demanda de acción de amparo, la misma que fue declarada improcedente liminarmente por la Primera Sala Civil de la Corte Superior de Justicia de La Libertad. Apelada esta sentencia de primera instancia es confirmada por la Sala de Derecho Constitucional y 
Social Permanente de la Corte Suprema de Justicia de la República, con fecha 17 de septiembre del 2008, por lo que la socia Flor de María Ibañez Salvador interpone recurso de agravio constitucional, el cual fue declarado finalmente fundado, ordenando a las empresas emplazadas que cumplan con restituir a la demandante la titularidad de todas las acciones que poseía en la Empresa Agraria Chiquitoy S.A.

\section{Temas a analizar}

En el presente análisis y comentario jurisprudencial abordaremos específicamente tres temas que juzgamos como los de mayor relevancia, a saber:

a) El derecho de suscripción preferente.

b) La reducción del capital social.

La operación acordeón.

\section{El derecho de suscripción preferente}

\section{Introducción}

El derecho de suscripción preferente (también denominado derecho de opción) es la preferencia de los socios frente a cualquier tercero para la suscripción de las acciones o participaciones a prorrata de su participación en el capital social cuando se acuerda aumentar éste mediante nuevos aportes con el propósito de respetar la proporción que, en dicho capital social, tiene cada socio, evitando así que la participación de éste quede diluida a propósito del referido aumento. La Ley General de Sociedades ${ }^{1}$ prescribe en su artículo 207:

\section{"Artículo 207. Derecho de suscripción preferente.-}

En el aumento de capital por nuevos aportes, los accionistas tienen derecho preferencial para suscribir, a prorrata de su participación accionaria, las acciones que se creen. Este derecho es transferible en la forma establecida en la presente Ley.
No pueden ejercer este derecho los accionistas que se encuentren en mora en el pago de los dividendos pasivos, y sus acciones no se computarán para establecer la prorrata de participación en el derecho de preferencia.

No existe derecho de suscripción preferente en el aumento de capital por conversión de obligaciones en acciones, en los casos de los artículos 103 y 259 ni en los casos de reorganización de sociedades establecidos en la presente Ley."

Las siguientes líneas no tienen por finalidad agotar el tema, sino más bien analizar algunas cuestiones específicas, varias de ellas especialmente controvertidas. Así, abordaremos el derecho de suscripción preferente en la sociedad anónima en el aumento de capital social por incremento del valor nominal de las acciones y por capitalización de créditos. También nos pronunciaremos sobre el derecho de suscripción preferente en la sociedad anónima para los titulares de acciones sin derecho a voto. Luego veremos aquellos casos en los que no existe el derecho de suscripción preferente. Proseguiremos con un tópico que ocasiona abundante discrepancia: la exclusión del derecho de suscripción preferente en la sociedad anónima mediante el estatuto social, el acuerdo de la junta de socios y el convenio parasocietario. Para concluir analizaremos si existe el derecho de suscripción preferente en la sociedad comercial de responsabilidad limitada y en las otras formas societarias distintas a la sociedad anónima.

\section{El derecho de suscripción preferente en la sociedad anónima en el aumento de capital social por incremento del valor nominal de las acciones}

El artículo 203 de la norma societaria estipula:

\footnotetext{
"Artículo 203. Efectos.-

El aumento de capital determina la creación de nuevas acciones o el incremento del valor nominal de las existentes." (El resaltado es nuestro).
} 
Cuando se aumenta el capital social de la sociedad anónima por incremento del valor nominal de las acciones no existe el derecho de suscripción preferente porque la proporción de cada socio respecto a su participación accionaria se mantiene incólume, no viéndose afectado entonces lo que se pretende cautelar mediante aquella figura societaria. Por ejemplo: Abril S.A. tiene un capital social de US\$10 mil, representado en 10 mil acciones con valor nominal de US\$ 1 cada una y cuenta con cuatro socios, siendo que cada cual ha suscrito 2,500 acciones y pagado US\$2,500. Si dicha sociedad incrementa el valor nominal de sus acciones de US\$1 a US\$ 1.50 entonces se habrá aumentado el capital social de US\$10 mil a US\$15 mil y cada uno de los cuatro socios seguirá siendo titular de 2,500 acciones (aunque el paquete accionario ahora tiene un mayor valor al haberse pasado de US\$2,500 a US\$3,750) y, lo más importante, su proporción respecto al capital social seguirá siendo la misma en uno y otro caso: $25 \%$.

\begin{tabular}{|c|c|c|c|}
\hline \multicolumn{5}{|c}{ El aumento del capital social por incremento del valor nominal de las } \\
acciones
\end{tabular}

\section{Notas}

1. Perú. Ley General de Sociedades. Aprobada mediante Ley № 26887 publicada en el Diario Oficial El Peruano el 9 de diciembre de 1997. 